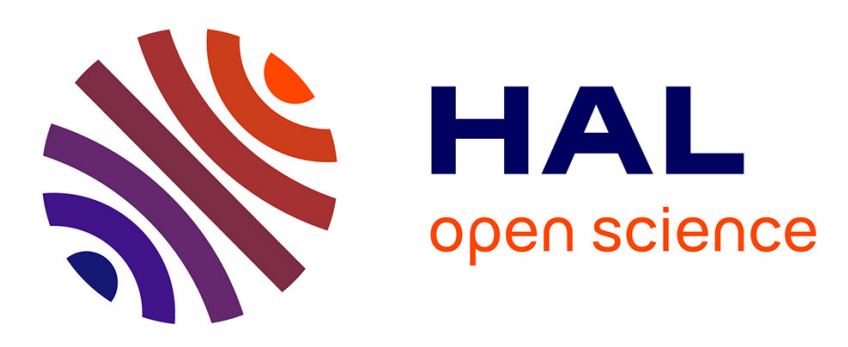

\title{
Response of precipitation extremes to warming: what have we learned from theory and idealized cloud-resolving simulations, and what remains to be learned?
}

\author{
Caroline Muller, Yukari Takayabu
}

\section{To cite this version:}

Caroline Muller, Yukari Takayabu. Response of precipitation extremes to warming: what have we learned from theory and idealized cloud-resolving simulations, and what remains to be learned? Environmental Research Letters, 2020, 15 (3), pp.035001. 10.1088/1748-9326/ab7130 . hal-02557032

\section{HAL Id: hal-02557032 \\ https://hal.sorbonne-universite.fr/hal-02557032}

Submitted on 28 Apr 2020

HAL is a multi-disciplinary open access archive for the deposit and dissemination of scientific research documents, whether they are published or not. The documents may come from teaching and research institutions in France or abroad, or from public or private research centers.
L'archive ouverte pluridisciplinaire HAL, est destinée au dépôt et à la diffusion de documents scientifiques de niveau recherche, publiés ou non, émanant des établissements d'enseignement et de recherche français ou étrangers, des laboratoires publics ou privés. 
LETTER • OPEN ACCESS

Response of precipitation extremes to warming: what have we learned from theory and idealized cloud-resolving simulations, and what remains to be learned?

To cite this article: Caroline Muller and Yukari Takayabu 2020 Environ. Res. Lett. 15035001

View the article online for updates and enhancements. 


\title{
LETTER
}

CrossMark

OPEN ACCESS

RECEIVED

5 September 2019

REVISED

16 January 2020

ACCEPTED FOR PUBLICATION

29 January 2020

PUBLISHED

18 February 2020

Original content from thi work may be used under the terms of the Creative

Commons Attribution 4.0 licence.

Any further distribution of this work must maintain

attribution to the

author(s) and the title of

the work, journal citation

and DOI.

\section{Response of precipitation extremes to warming: what have we learned from theory and idealized cloud-resolving simulations, and what remains to be learned?}

\author{
Caroline Muller ${ }^{1}$ and Yukari Takayabu \\ 1 CNRS, Laboratoire de Météorologie Dynamique/Institut Pierre Simon Laplace, École Normale Supérieure, Paris, France \\ 2 The University of Tokyo, Chiba, Japan \\ E-mail: muller@lmd.ens.fr
}

Keywords: precipitation extremes, tropical convection, radiative-convective equilibrium

\begin{abstract}
This paper reviews recent important advances in our understanding of the response of precipitation extremes to warming from theory and from idealized cloud-resolving simulations. A theoretical scaling for precipitation extremes has been proposed and refined in the past decades, allowing to address separately the contributions from the thermodynamics, the dynamics and the microphysics. Theoretical constraints, as well as remaining uncertainties, associated with each of these three contributions to precipitation extremes, are discussed. Notably, although to leading order precipitation extremes seem to follow the thermodynamic theoretical expectation in idealized simulations, considerable uncertainty remains regarding the response of the dynamics and of the microphysics to warming, and considerable departure from this theoretical expectation is found in observations and in more realistic simulations. We also emphasize key outstanding questions, in particular the response of mesoscale convective organization to warming. Observations suggest that extreme rainfall often comes from an organized system in very moist environments. Improved understanding of the physical processes behind convective organization is needed in order to achieve accurate extreme rainfall prediction in our current, and in a warming climate.
\end{abstract}

\section{Introduction}

In recent decades, there have been important fundamental advances in our understanding of the response of precipitation extremes to warming. Global climate models (GCMs) used for climate prediction, disagree on the amplitude of the response of precipitation extremes, especially in the tropics where they largely rely on convective parameterizations to represent deep cloud dynamics and deep convection (Kharin et al 2007). Thus, progress on this question must also rely on observations, theory, and high-resolution numerical simulations which resolve deep convection, instead of parameterizing it.

One difficulty with observations is that the dependence of precipitation extremes on temperature variations in our current climate, is not necessarily the same as its dependence on temperature under climate change (O'Gorman 2012). Also the response of precipitation extremes to warming might differ at different spatial and temporal scales (Utsumi et al 2011). Extreme rainfall intensity, frequency and duration (e.g. instantaneous, hourly or daily extreme rainfall rates) are all important for floods and risks.

It has become standard to phrase the response of precipitation extremes to increasing temperatures, in terms of the increase in atmospheric water vapor. If changes in relative humidity are small, atmospheric humidity is expected to increase roughly exponentially with temperature following the Clausius-Clapeyron equation, or 'CC-scaling' (Trenberth et al 2003, Pall et al 2007), at a rate of about $7 \%-8 \% \mathrm{~K}^{-1}$ (though the precise value depends on latitude O'Gorman and Muller 2010). Indeed, if the conditions under which the precipitation forms remain unchanged and only atmospheric water vapor increases, then precipitation extremes can be expected to scale with the increased available humidity in the atmosphere. 
There is now ample empirical evidence of significant departure of the precipitation extremestemperature relationship from this CC-scaling in observations and simulations, as recently reviewed by Westra et al (2014). Rates of increase of up to double the $\mathrm{CC}$ rate have been observed for subdaily precipitation extremes for temperatures up to about $20^{\circ} \mathrm{C}$ (although this value is regionally variable, e.g. Drobinski et al 2016b), with decrease at warmer temperatures. Notably, subdaily precipitation extremes could be more sensitive to changes in local atmospheric temperature than daily precipitation (Westra et al 2014). Possible explanations for this departure from CC-scaling include event duration (Utsumi et al 2011), change of precipitation type (convective versus stratiform) (Berg and Haerter 2013), land/ocean contrasts with aridity and moisture limitation at warmer temperatures (Hardwick Jones et al 2010), dynamical effects (Singleton and Toumi 2013), or convective organization (Bao and Sherwood 2019).

GCMs also show a wide variety of rates of increase of precipitation extremes with increasing surface temperatures, as recently reviewed by O'Gorman (2015). This is especially true in the tropics where the intermodel range is largest. Interestingly, the modeled sensitivity of precipitation extremes to global warming, is correlated with their sensitivity to shorter term natural climate variability (dominated by El-Niño Southern Oscillation, or ENSO) (O'Gorman 2012). Thus, GCM sensitivities can be constrained using this robust relationship between sensitivities for climate change and for variability, along with observations of tropical variability. The sensitivities of the 99.9th percentile of daily precipitation inferred for climate change confirm the highest sensitivity and uncertainty in the tropics (O'Gorman 2015), due to the small-scale nature of convective precipitation there.

In the extratropics, precipitation extremes are generally associated with larger-scale frontal systems, thus better resolved in GCMs. Accordingly, the intermodel scatter of precipitation extremes changes with warming, is smaller at midlatitudes (Kharin et al 2007, O'Gorman 2015). We note though that there remain important outstanding questions on extratropical precipitation extremes, notably the role of ocean-atmosphere interactions, snowfall extremes, the role of orography, or extremes associated with long-lived mesoscale convective systems over midlatitudes in summer. These are beyond the scope of this review, but the interested reader is referred to O'Gorman (2015) and references therein for a more in-depth discussion.

Instead here, we will focus on tropical precipitation extremes, and will review recent theoretical and idealized studies, in order to highlight robust results and responses. We will also review key outstanding questions and uncertainties that these idealized studies either raise, or do not include. We will first review the theoretical basis for the thermodynamic CC-scaling.
We will then discuss the other contributions to precipitation extremes, which can lead to departures from the CC rate, with a particular emphasis on recently identified theoretical constraints on those additional contributions.

Theory and high-resolution simulations have helped clarify the relevant physics. Notably, a theoretical scaling for precipitation extremes has been introduced (Betts and Harshvardhan 1987, O'Gorman and Schneider 2009) and refined to account for microphysics (Muller et al 2011). It relates the changes of precipitation extremes to three contributions: a thermodynamic contribution related to water vapor (the 'CC-scaling' mentioned above), a dynamic contribution related to vertical mass flux in extreme updrafts, and a microphysic contribution related to precipitation efficiency. The latter is defined as the fraction of the condensation in a convective updraft which eventually reaches the surface as precipitation. It is typically less than one as some of the condensates are either advected away as clouds, or evaporate as they precipitate through unsaturated air below the cloud before reaching the surface. Each of these three contributions is subject to different theoretical constraints, and may respond differently to warming.

In this paper, we provide a brief overview of the origin of this theoretical scaling. It can be derived from energetics, or from the water budget. We will review the former approach, and its link to the water budget. Recent theoretical advances on the three contributions to precipitation extremes and their response to warming will also be presented. Questions of particular interest are:

- By how much do precipitation extremes increase with warming, and how does it compare to the thermodynamic contribution expected from the theoretical scaling?

- How do vertical velocities in updrafts change, and how does it relate to the dynamic contribution to precipitation extremes?

- How does the microphysic contribution to the theoretical scaling, through changes in precipitation efficiency, respond to warming?

As mentioned above, we will focus on tropical precipitation extremes, where the disagreement between GCMs is largest, due to the small-scale nature of tropical convection. The focus on tropical precipitation extremes is also motivated by the fact that it allows comparison with cloud-resolving model (CRM) simulations in non-rotating radiative-convective equilibrium (RCE). RCE is an idealization of the tropical atmosphere, where the large-scale circulation (larger than the domain size) is neglected. In other words, there is no import or export of energy into or out of the domain. Non-rotating RCE further neglects the 
Coriolis force, a reasonable approximation in the deep tropics where the Coriolis parameter is small. As we will see, such idealized simulations have proven extremely useful in improving our understanding of the physical processes at stake. The intriguing fact that a comprehensive GCM run in RCE can reproduce reasonably well the tropical climate, and explain $50 \%$ of the climate sensitivity of realistic GCM runs (part of the discrepancy being attributable to the lack of polar amplification in RCE) also provides some evidence that this is a valid comparison to make (Popke et al 2013).

Beyond these idealized theoretical and numerical investigations, observations of the processes behind precipitation extremes in our current climate can help shed some light on projections of precipitation extremes in future climate. Observations of extreme convection versus extreme rainfall highlight the importance of organized systems. These recent results, as well as implications for extreme rainfall rates in our warming climate, will be discussed.

The paper is laid out as follows; section 2 reviews the derivation of the theoretical scaling for precipitation extremes. Theoretical expectations from this scaling are compared to CRM simulations in section 3. This comparison highlights the importance of the thermodynamic contribution, due to increased boundary layer water vapor with warming. Changes in vertical velocities in extreme updrafts with warming are investigated in section 4 , where CRM results are interpreted in light of a zero-buoyancy plume model, and implications for the dynamic contribution to precipitation extremes are discussed. Section 5 summarizes recent results and outstanding uncertainties regarding the microphysic contribution, related to precipitation efficiency. Results from observations are presented in section 6, and conclusions, as well as key outstanding open questions, are discussed in section 7 .

\section{Theoretical scaling for precipitation extremes}

\subsection{Derivation of the scaling}

A scaling for precipitation extremes can be derived from energetics, using the vertically-integrated dry static energy (DSE) budget (Muller et al 2011). An energy rather than a water budget is used because an energy budget allows to more easily define a thermodynamic component (no dependence on relative humidity), and because the weak horizontal temperature gradients in the tropics allow to eliminate the horizontal advection terms Following (Muller et al 2011), we use the thermodynamic formulation consistent with the CRM 'System for Atmospheric Modeling' (SAM; see Khairoutdinov and Randall 2003 for a detailed description), and using standard notations the DSE budget becomes:

$$
\begin{aligned}
\int \frac{D s}{D t} \rho d z= & L_{v} \int \frac{D\left(q_{r}+q_{c}\right)}{D t} \rho d z \\
& +L_{s} \int \frac{D\left(q_{s}+q_{g}+q_{i}\right)}{D t} \rho d z+L_{v} P
\end{aligned}
$$

where $s=c_{p} T+g z$ denotes DSE, $\rho(z)$ the mean density profile, $P$ surface precipitation (only involving the liquid phase at typical tropical temperatures) and $q_{r}, q_{c}, q_{s}, q_{g}, q_{i}$ denote the mixing ratios of respectively liquid rain, liquid cloud condensates, snow, graupel and cloud ice (all water condensates in SAM). The Lagrangian derivative is given by

$$
\frac{D}{D t}=\frac{\partial}{\partial t}+u_{i} \frac{\partial}{\partial x_{i}}
$$

with $u_{i}$ resolved wind speed along the $x_{i}$ direction, $1 \leqslant i \leqslant 3$ (note that the total vertical flux of condensates includes both the resolved vertical velocity, included in the $D / D t$ term, and the terminal fall speed of hydrometeors, included in the precipitation term, see Khairoutdinov and Randall 2003 for details). The mass weighted integral $\int(\ldots) \rho d z$ is taken from the surface to the tropopause.

Note that this is a local energy budget, i.e. meant to be evaluated locally in the extreme event. Thus subgrid-scale fluxes and radiative cooling contributions have been neglected in the DSE budget, anticipating that those terms are negligible compared to the latent heat terms at locations of extreme rainfall.

Also, at extremes, the time rate of change of DSE is largely dominated by the vertical advection (due to both strong updrafts and weak horizontal temperature gradients):

$$
\frac{D s}{D t} \approx w \frac{\partial s}{\partial z} .
$$

If we further neglect the difference between $L_{v}$ and $L_{s}$ for the purpose of deriving a simple approximate expression, and if we assume that the tropical atmosphere is close to a moist adiabat $d s \approx-L_{v} d q_{\text {sat }}$ where $q_{\text {sat }}$ denotes saturation mixing ratio, then

$$
\frac{\partial s}{\partial z} \approx-L_{v} \frac{\partial q_{s a t}}{\partial z},
$$

and (1) becomes

$$
\begin{aligned}
P_{e} \approx & \int \rho w\left(-\frac{\partial q_{s a t}}{\partial z}\right) d z \\
& -\int \rho \frac{D\left(q_{r}+q_{c}+q_{s}+q_{g}+q_{i}\right)}{D t} d z .
\end{aligned}
$$

This yields the following scaling for precipitation extremes

$$
P_{e}=\epsilon \int \rho w\left(-\frac{\partial q_{s a t}}{\partial z}\right) d z,
$$

where $\epsilon$ denotes a precipitation efficiency. Although this scaling has been derived from energetics, it resembles a water budget and can be interpreted as such. The first integral on the right hand side of (3) represents the total net condensation (and deposition) 

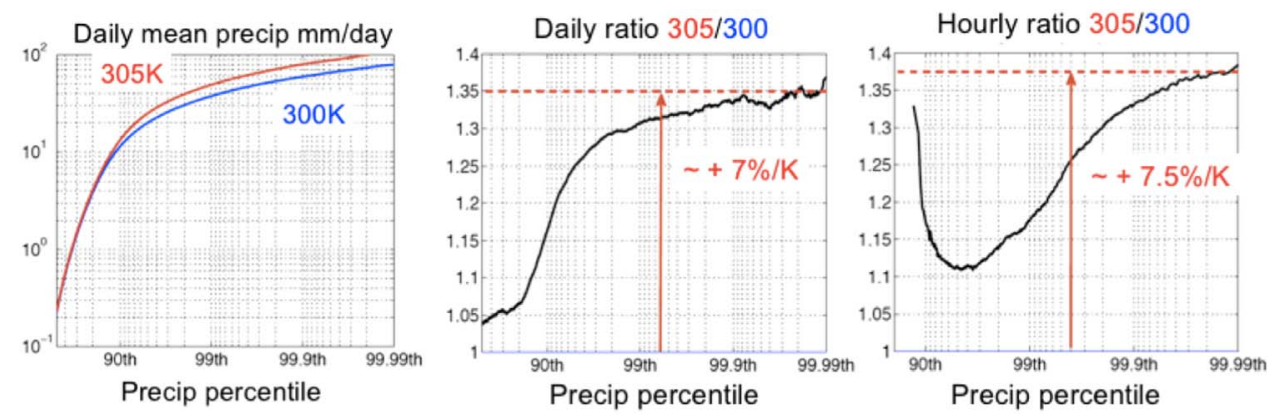

Figure 1. Values of daily precipitation extremes (i.e. high percentiles, left panel) in the cold (blue) and warm (red) simulations. The ratio between the warm and cold rainfall rates is shown in the middle panel. Similar results are obtained at hourly time scales (right panel, after Muller et al 2011), reproduced with permission, copyright [2011] AMS.

in the updraft (assumed saturated), including condensation from upward motion as well as evaporation of condensates maintaining a moist adiabat in downdrafts. A fraction $\epsilon$ of this net condensation reaches the surface as precipitation, thus we refer to $\epsilon$ as precipitation efficiency. In the limit $\epsilon=1$, all the net condensates precipitate out; in the limit $\epsilon=0$, all condensates are advected from or accumulate in the column over the time scaling in question (second term on the right hand side of (3)).

As mentioned earlier, this is a local scaling, i.e. meant to be evaluated at locations of precipitation extremes. One worry then, is the potential sensitivity to spatial and temporal averaging. Muller et al (2011) investigate hourly versus daily precipitation extremes (their figure 4, see also figure 1 below), as well as coarse-grained results (from 2 to $24 \mathrm{~km}$ horizontal extent, their figure 6). The results are extremely robust and the scaling shows excellent agreement with precipitation extremes amplification with warming in cloud-resolving simulations. Therefore, although the value of precipitation extremes is sensitive to spatial/ temporal averaging, its amplification with warming seems to be robust and to be well captured by this scaling, at least in idealized RCE simulations as discussed in more detail in the next section. We note however that this result is not necessarily robust in more realistic simulations and in observations (Westra et al 2014). Notably, Lenderink et al (2019) investigate the amplification of precipitation extremes in warming experiments over western Central Europe and over western Mediterranean. They find that the amplification is in general stronger at CRM resolution (convection-permitting regional climate model with $2-3 \mathrm{~km}$ horizontal resolution) than at coarser resolution (conventional regional climate model with $12-15 \mathrm{~km}$ horizontal resolution). This difference between sensitivity to resolution in idealized versus more realistic studies, is in our opinion interesting and deserves further investigation (see section 6 for a more in-depth discussion).

As it involves net condensation (condensation minus evaporation), $\epsilon$ differs slightly from the conventional precipitation efficiency defined as the fraction of total condensation reaching the surface as precipitation. Alternatively, if the integration in (4) is limited to heights where $w>0$ as is sometimes the case in the literature, then $\epsilon$ represents the conventional precipitation efficiency. Similar scalings were derived prior to Muller et al (2011) for precipitation extremes (Iribarne and Godson 1981, Betts and Harshvardhan 1987, O'Gorman and Schneider 2009, Sugiyama et al 2010), except that in (4) $w$ is now at the convective scale, and there is the additional factor involving precipitation efficiency.

We note that (Abbott et al 2019) recently further refined this scaling, noting that the mass flux profiles collapse to a common shape across various climates when plotted in a moisture-based vertical coordinate. In other words, the integral can be simplified if expressed using $q_{\text {sat }} / q_{\text {sat sfc }}$ as vertical coordinate (i.e. saturation specific humidity normalized by saturation specific humidity at the surface).

We also note that in pressure coordinates, the scaling becomes

$$
P_{e}=-\epsilon \int \omega \frac{\partial q_{s a t}}{\partial p} \frac{d p}{g},
$$

where $\omega$ denotes pressure vertical velocity (in $\mathrm{hPa} \mathrm{s}^{-1}$ ). In the extratropics, where the atmosphere is not necessarily on a moist adiabat, the scaling can be extended, replacing the vertical derivative by a derivative along a moist adiabat, i.e. with constant saturation equivalent potential temperature $\theta_{e, \text { sat }}$ (O'Gorman and Schneider 2009, O’Gorman 2015)

$$
\left.\frac{\partial q_{s a t}}{\partial p}\right|_{\theta_{e, s a t}}
$$

\subsection{Using the scaling to split precipitation extremes into three contributions}

The scaling in (4) can be used to relate changes of precipitation extremes, to changes of the dynamics through the mass flux $\rho w$, of the thermodynamics through $\partial q_{\text {sat }} / \partial z$, and of the microphysics through $\epsilon$ 


$$
\begin{gathered}
\frac{\delta P_{e}}{P_{e}} \approx \underbrace{\frac{\delta\left(\epsilon \int \rho w\left(-\frac{\partial q_{s a t}}{\partial z}\right) d z\right)}{\epsilon \int \rho w\left(-\frac{\partial q_{s a t}}{\partial z}\right) d z}}_{\text {scaling }} \\
\approx \underbrace{\frac{\delta \epsilon}{\epsilon}+\underbrace{\int \delta(\rho w)\left(-\frac{\partial q_{s a t}}{\partial z}\right) d z}_{\text {dynamic }}}_{\text {microphysic }} \\
+\underbrace{\frac{\int \rho w\left(-\frac{\partial q_{\text {sat }}}{\partial z}\right) d z}{\int \rho w\left(-\frac{\partial q_{s a t}}{\partial z}\right) d z}}_{\text {thermodynamic }}
\end{gathered}
$$

where $\delta$ denotes a difference between a warm and a cold climate, and following (Muller et al 2011, Muller 2013) we neglected second-order terms.

Assuming that changes in precipitation efficiency are small with warming, changes in precipitation extremes can be related to changes in the dynamics and in the thermodynamics (second and third terms on the right hand side of (8)). This simple scaling is found to be in very good agreement with cloud-resolving simulations in non-rotating RCE, as discussed in more detail in the next section.

\section{Comparison with cloud-resolving simulations, and thermodynamic contribution}

\subsection{Numerical results}

Extremes, i.e. high percentiles, of daily precipitation in cloud-resolving simulations in non-rotating RCE at sea-surface temperatures (SSTs) of 300 and $305 \mathrm{~K}$ are shown in the left panel of figure 1 (adapted from Muller et al 2011). Extremes are computed over all times and all points in space (including both wet and dry days). We note that defining extremes based on wet days only (when precipitation exceeds a certain threshold) can yield quantitatively different statistics, notably in cases where significant changes in the wetday frequency occur and are not accounted for Schär etal(2016).

For a given percentile, the corresponding rainfall rate is always larger in the warmer simulation. Consistently, the ratio between precipitation percentiles in the warm and in the cold runs is above 1 . This ratio is shown in the middle panel for daily precipitation, and in the right panel for hourly precipitation. Although the values of precipitation extremes are sensitive to the temporal average, the ratio is not. In other words, the fractional increase in precipitation extremes is robust to the time scale used, and asymptotes in both cases at the highest percentiles to $\approx 7 \% \mathrm{~K}^{-1}$.

From figure 2, this increase is remarkably well captured by the scaling (7) neglecting changes in precipitation efficiency (i.e. only accounting for the thermodynamic and dynamic contributions). To first order, the amplification of precipitation extremes is well captured by the thermodynamic scaling, which is close to the low-level water vapor increase, and smaller than the atmospheric water vapor increase. The dynamics play a secondary role, and tend to oppose the amplification of extreme rainfall rates with warming.

\subsection{Approximate scaling and thermodynamic contribution}

If the dynamics of convective updrafts do not change with warming, the thermodynamic contribution to precipitation extremes could be expected to scale with the moisture convergence into deep convective updrafts, which would then scale with water vapor following the Clausius-Clapeyron equation (assuming small changes in relative humidity). But these numerical results suggest that we can instead expect tropical precipitation extremes to follow the low-level water vapor, which increases at a smaller pace than atmospheric water vapor (following boundary-layer Clausius-Clapeyron).

The fact that precipitation extremes follow lowtropospheric humidity, and not atmospheric humidity, can be understood using a simplified scaling derived from (4) (Muller 2013). Indeed, if we assume that the mass flux $\rho w$ at $500 \mathrm{hPa}$ is a representative value for $\rho w$ :

$$
\begin{aligned}
& \delta P_{e} \approx \delta\left(\int-\frac{\partial q_{\text {sat }}}{\partial z} \rho w d z\right) \\
\approx & \delta\left((\rho w)_{500 h P a} \int-\frac{\partial q_{s a t}}{\partial z} d z\right) \\
\approx & \underbrace{\delta\left((\rho w)_{500 h P a} q_{\text {sat }, B L}\right)}_{\text {simplifiedscaling }},
\end{aligned}
$$

where $q_{s a t, B L}$ denotes the saturation specific humidity in the boundary layer. If changes in relative humidity are small, the thermodynamic contribution to precipitation extremes is thus expected to follow lowtropospheric water vapor, consistent with the numerical results discussed above.

Similar increases in precipitation extremes, close to low-tropospheric moisture, have been found in another idealized study using a different CRM (Romps 2011), suggesting robustness to the model used, although more CRM studies beyond those two are needed to assess robustness with confidence. Abbott et al (2019) further confirm the dominance of the thermodynamic contribution to changes in instantaneous precipitation extremes, following near-surface moisture, across a wide range of climates. In the tropics, GCMs predict an increase of water vapor larger than $8 \% \mathrm{~K}^{-1}$ (O'Gorman and Muller 2010). If instead precipitation extremes follow low-tropospheric water vapor as suggested by the aforementioned CRM studies, the rate of increase is significantly reduced, to less than $6 \% \mathrm{~K}^{-1}$ (O'Gorman and Muller 2010). 


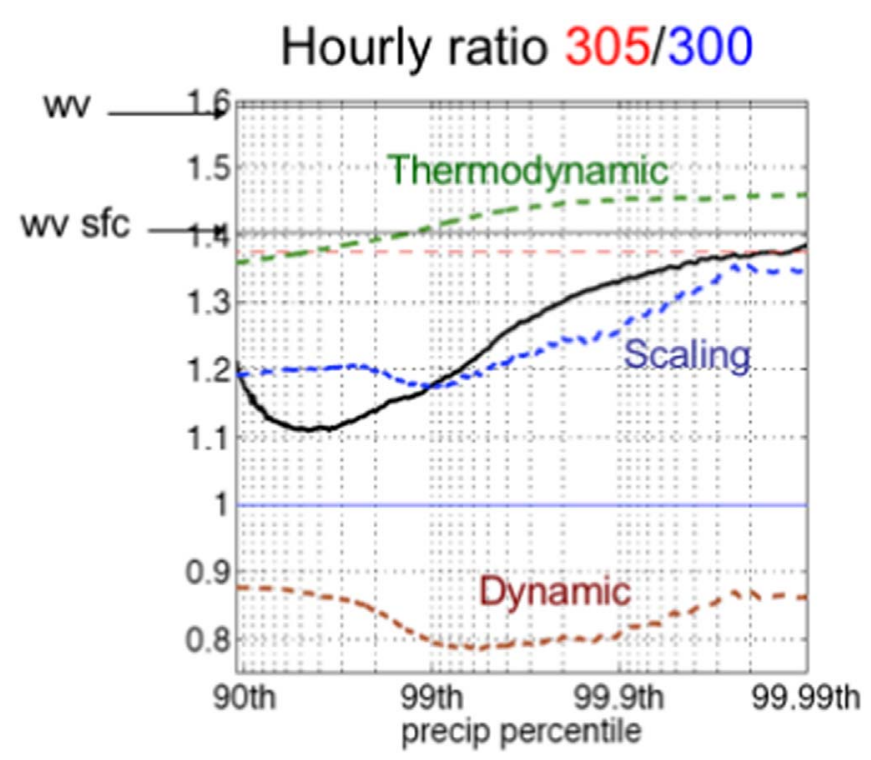

Figure 2. Increase in high percentiles (black curve) of hourly mean precipitation when the SST is increased from 300 to $305 \mathrm{~K}$ in CRM simulations, and comparison with the theoretical scaling (8) (blue curve) involving a dynamic and a thermodynamic contribution. The increase in atmospheric water vapor (wv) and low-tropospheric water vapor (wv sfc) are also shown. The amplification of extremes asymptotes $\approx 7 \% \mathrm{~K}^{-1}$ at the highest percentiles (ratio of about 1.35, red line, for a $5 \mathrm{~K}$ warming). Figure after (Muller et al 2011), reproduced with permission, copyright [2011] AMS.

Faster increases in precipitation extremes with warming have been found in CRM simulations of squall lines, when the warming is uniform in height (Singleton and Toumi 2013), a situation more relevant to the mid latitudes. In the tropics, one expects the atmosphere to warm following a moist adiabat, with larger warming aloft, as was the case in the CRM studies discussed above. If instead the warming is uniform with height, atmospheric instability is enhanced (Loriaux et al 2013). Consistently, faster updrafts contribute positively to the dynamic contribution, yielding amplifications of precipitation extremes with warming exceeding significantly the thermodynamic theoretical expectation (Singleton and Toumi 2013). The dynamic contribution will be discussed in more detail in the next section.

\section{Dynamic contribution}

The dynamic contribution was found to play a secondary role compared to the leading-order thermodynamic contribution in idealized CRM simulations, and was slightly weakening the amplification of precipitation extremes with warming. This dynamic contribution is related, though not equal to, vertical velocity in extreme updrafts $w$. In this section, we review recent theoretical advances on estimates for vertical velocities in updrafts and their sensitivity to warming. We then discuss its relationship with the dynamic contribution to precipitation extremes.

\subsection{Theory for CAPE, and response to warming} Convective Available Potential Energy (CAPE), defined as the vertically integrated buoyancy of adiabatically lifted undilute subcloud air, measures the potential energy available for convection. It provides an upper bound for $\frac{1}{2} w^{2}$ as it is related to the maximum amount of kinetic energy available for convection. Consistently, it is routinely used in weather centers to issue severe storm warnings, and predict e.g. thunderstorm severity (Brooks et al 1994), or precipitation extremes (Lepore et al 2015).

Recent work has produced a theoretical scaling for CAPE and its response to warming (Singh and O'Gorman 2013, Seeley and Romps 2015), using a zerobuoyancy plume model. In this model, the atmosphere is assumed to be neutral to an entraining plume (entraining plume models are widely used simplified representations of an ensemble of convective clouds Tiedtke 1989). In other words, clouds are assumed to have zero buoyancy, an assumption motivated by the relative smallness of cloud buoyancy compared to CAPE in CRM simulations (Muller et al 2011). CAPE is thus proportional to the temperature difference $\Delta T$ (neglecting virtual effects) between a hypothetical undilute subcloud parcel lifted adiabatically, and the temperature of the entraining plume.

The undilute parcel has Moist Static Energy (MSE $=$ DSE $+L_{v} q_{v}$ where $q_{v}$ denotes water vapor specific humidity), denoted $h_{u}$, constant with height: $d h_{u} / d z=0$. The environment being neutral to the entraining plume, the latter thus has temperature equal to that of the environment $T_{e}$ (again, neglecting virtual effects). Noting that the cloudy plume is saturated above cloud base, its MSE is given by $h_{e, s a t}=$ $c_{p} T_{e}+g z+L_{v} q_{v, s a t}\left(T_{e}\right)$ and it satisfies the plume equation 

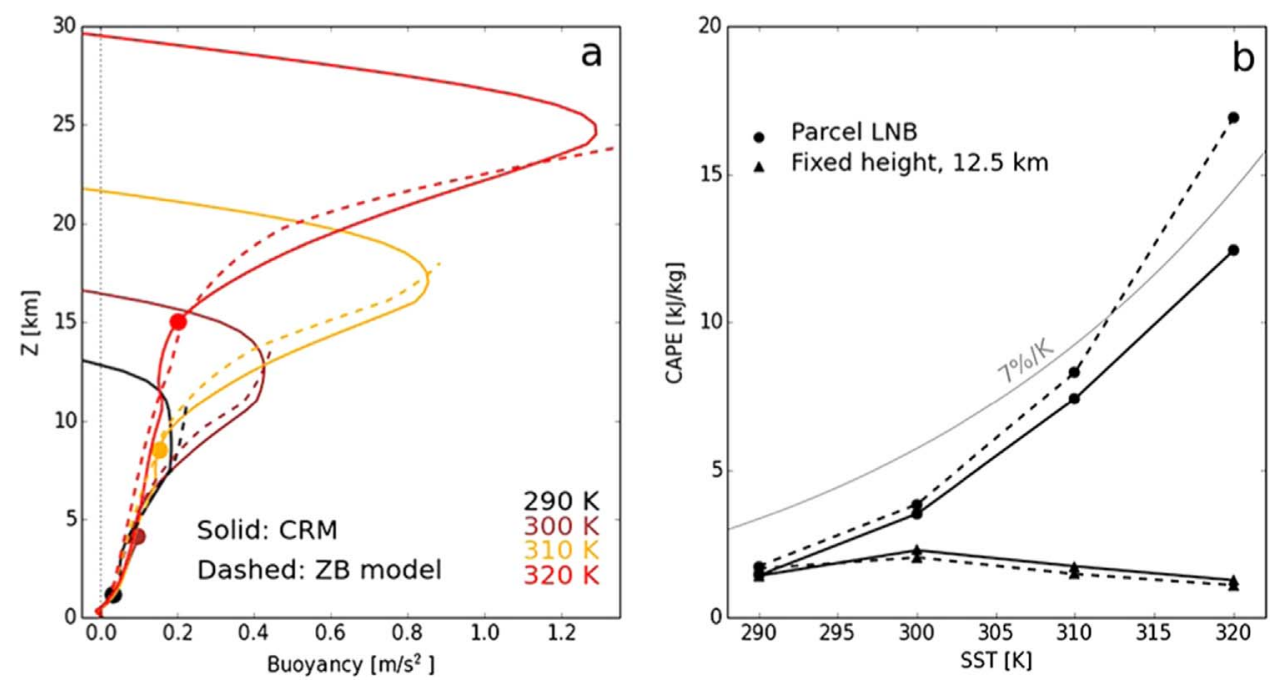

Figure 3. (a) Buoyancy profiles of adiabatically-lifted near-surface parcels in a CRM (plain) and expected from the zero-buoyancy plume mode (dashed), when SST is varied from 290 to $320 \mathrm{~K}$. The plain color circles indicate the height above which the denominator in (13) is dominated by $c_{p}$. (b) CAPE response to SST changes in the CRM (plain) and from the zero-buoyancy plume model (dashed). The Clausius-Clapeyron scaling of $7 \% \mathrm{~K}^{-1}$ is also shown for reference, as well as CAPE when integration is performed up to a fixed height not varying with SST, instead of integrating to the level of neutral buoyancy (LNB diagnosed from the CRM simulation). Figure after (Seeley and Romps 2015), reproduced with permission, copyright [2015] AGU.

$\frac{\partial h_{e, s a t}}{\partial z}=-\nu\left(h_{e, s a t}-h_{e}\right)=-\nu L_{\nu}(1-R H) q_{s a t, e}$,

where $\nu$ denotes fractional entrainment rate $\left(\right.$ in $\mathrm{m}^{-1}$ ), $R H$ relative humidity of the environment, and where we have used the fact that the plume is saturated $q_{\text {sat }, e}=q_{v, \text { sat }}\left(T_{e}\right)$. Noting that

$$
\begin{aligned}
\Delta h & =h_{u}-h_{e, s a t}=\left(c_{p}+L_{v} \frac{\partial q_{s a t, e}}{\partial T}\right) \Delta T \\
& =\left(c_{p}+\frac{L_{v}^{2}}{R_{v} T_{e}^{2}} q_{s a t, e}\right) \Delta T,
\end{aligned}
$$

and that $d \Delta h / d z=-d h_{e, s a t} / d z$, one obtains

$$
\Delta T(z)=\frac{1}{c_{p}+\frac{L_{v}^{2}}{R_{v} T_{e}^{2}} q_{s a t, e}} \int^{z} L_{v} \nu(1-R H) q_{s a t, e} d z,
$$

where the integration is performed from cloud base (entrainment is assumed to act only above cloud base).

Figure 3 shows the buoyancy profiles at different SSTs in a CRM, as well as those expected from this zero-buoyancy plume model. The figure also shows the response of CAPE to SST variations (Seeley and Romps 2015). For the CAPE computation, since the zero-buoyancy plume model does not predict the height of convection (from (13)), the integration is performed up to the level of neutral buoyancy diagnosed from the CRM simulations. The fractional entrainment rate is assumed to decay in $1 / z$ (Holloway and Neelin 2009).

The plume model reproduces remarkably well the behavior of buoyancy and CAPE. CAPE is found to increase with SST roughly following Clausius-
Clapeyron scaling. As can be seen from figure 3(b), this increase comes from the upper atmosphere. It is due to two contributions: increased height reached by convection at warmer temperatures (Hartmann and Larson 2002), and increased saturation specific humidity with warming $q_{\text {sat, }}$ in the numerator in (13). Physically, this latter contribution leads to an increased saturation deficit $(1-\mathrm{RH}) q_{\text {sat,e }}$, itself leading to more effect of entrainment at warmer temperatures, and thus more temperature difference between the undilute and the entraining plumes. Note that at low levels, the denominator also scales with $q_{\text {sat,e }}$ (leading term in the denominator up to the altitudes of the filled colored circles in figure 3(a)), which explains why this contribution is dominated by upper atmospheric levels.

We also note that a recent theoretical model, derived in the specific case of severe weather over continents, shows a similar increase in CAPE, following Clausius-Clapeyron over a range of surface temperatures (Agard and Emanuel 2017). Unlike what was presented above, in that study CAPE is not estimated from a scaling derived in equilibrium. Instead, maximum transient CAPE, in response to a diurnal cycle of surface fluxes, is estimated. These results suggest a potential occurrence of increased severe continental convection in warmer climates.

\subsection{CAPE, buoyancy, and $w$}

This fast increase in CAPE with warming does not necessarily imply a similar increase of cloud buoyancy $B$ and thus vertical updraft velocities $w$. Indeed, $\frac{1}{2} w^{2}$ is typically found to increase with warming, but at a rate close to the increase in $B$, smaller than that of CAPE 
(Muller et al 2011, Singh and O'Gorman 2013). Singh and O'Gorman (2015) investigated this behavior using an extension of the zero-buoyancy plume model discussed in the previous section, into a two-plume model. In the latter, a weakly entraining plume represents the most intense updrafts, and the environment is again assumed to adjust to a zero-buoyancy entraining plume. In other words, typical updrafts are represented as an entraining plume with a relatively strong entrainment rate, while the most extreme updrafts are represented as a second entraining plume with weaker entrainment rate.

This two-plume model reproduces the slower increase with warming of $B$ and extreme updraft velocities compared to CAPE in CRM simulations. Thus, updraft velocities increase with warming at a lower fractional rate than CAPE because of the influence of entrainment on both the mean stratification and the updrafts themselves. But fairly low entrainment rates need to be used for the weakly entraining plume to match the CRM results. This suggests that this twoplume model may be successful in capturing the physics responsible for this contrasting behaviour between CAPE and $B$, but more work is desirable to quantitatively clarify the amplification of extreme updraft speeds with warming and its link with entrainment. Notably, the role of microphysics, and in particular of the terminal velocity of precipitating condensates on updraft velocities, remains unclear (Parodi and Emanuel 2009, Singh and O'Gorman 2015). Further investigation of the robustness of these results at higher resolution as well as in observations would be welcome. Entrainment processes, which are found to be key, are not well represented at CRM resolutions (typically kilometric horizontal resolutions) used in the aforementioned studies. Evidence of similar entrainment ranges and of the rarity of undilute ascent in higher resolution simulations exist, but remain scarce (e.g. Romps and Kuang 2010).

\subsection{Dynamic contribution to precipitation extremes} Increased vertical velocities in extreme updrafts do not necessarily imply larger precipitation extremes (Singh and O'Gorman 2015). The dynamic contribution to precipitation extremes is indeed related to the convective mass flux $\rho w$, not $w$ itself. In some warming CRM simulations, (Muller 2013) even find that high percentiles of the convective mass flux $\rho w$ can decrease while high percentiles of $w$ increase.

It is unclear how extreme convective mass fluxes should change with warming. The mean mass flux $M$ on the other hand (averaged over all upward convecting regions) is expected to decrease (Betts 1998, Held and Soden 2006). Indeed, it can be estimated from the mean precipitation $P$ and near-surface specific humidity $q_{v, B L}$, noting that $P \approx M q_{v, B L}$, thus

$$
\frac{\delta M}{M} \approx \frac{\delta P}{P}-\frac{\delta q_{v, B L}}{q_{v, B L}} .
$$

Unlike precipitation extremes, mean precipitation changes are constrained by the mean energetics (Trenberth 1998, Allen and Ingram 2002, Held and Soden 2006, Muller and O'Gorman 2011). In RCE simulations over oceans, where sensible heat fluxes are small compared to latent heat fluxes, this yields an increase in mean precipitation following radiative cooling changes, with slower increase $\left(\approx 2-3 \% \mathrm{~K}^{-1}\right)$ than specific humidity changes which follow Clausius-Clapeyron $\left(\approx 6-7 \% \mathrm{~K}^{-1}\right)$. Consistently, the mean mass flux decreases at a rate of about $3-4 \% \mathrm{~K}^{-1}$.

But this decrease in mean mass flux does not necessarily entail a decrease in convective mass flux in extreme updrafts. Nor does it necessarily imply a decreased mean upward velocity in the ascending branch of the tropical circulation, due to a potential tightening of the ascent area (Su et al 2019). Changes in skewness of the vertical velocity distribution (Pendergrass and Gerber 2016), and changes in precipitation frequency with convective organization also complicate the picture (less convective events with the same individual mass fluxes yield a smaller mean mass flux Muller 2013). Given its impact on precipitation extremes, more work is desirable to investigate in detail the distribution of convective mass flux, its link with entrainment and condensate fall speed, and its response to warming.

We note that the intermodel scatter between GCM estimates of tropical precipitation extremes mentioned in the introduction can be traced back to the dynamic contribution. This is true for both tropical precipitation extremes (O'Gorman and Schneider 2009, Sugiyama et al 2010) and for smaller regional scales (Pfahl et al 2017). Although the scales are different from the convective scales investigated in CRM simulations, this further highlights the need to improve our fundamental understanding of the uncertain dynamic contribution to precipitation extremes, in order to reduce uncertainties in future projections of precipitation extremes.

\section{Microphysic contribution}

The microphysic contribution to precipitation extremes is related to the precipitation efficiency $\epsilon$ in (4). As mentioned earlier, if the integral is performed over heights where $w>0$, then $\epsilon$ represents the conventional precipitation efficiency, namely the fraction of total condensation which reaches the surface as precipitation. If the integration is performed at all heights, then $\epsilon$ differs slightly from this classical definition as it represents the fraction of net condensation (condensation minus evaporation) reaching the ground. In this section, we will review recent results regarding the former, which is the conventional definition of precipitation efficiency.

Precipitation efficiency and its response to warming remain poorly understood and poorly constrained. 
a)Precipitation Efficiency

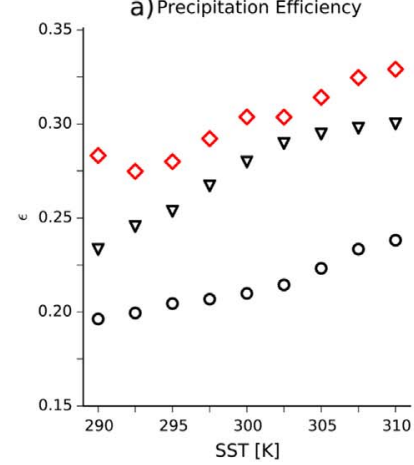

b) Conversion Efficiency

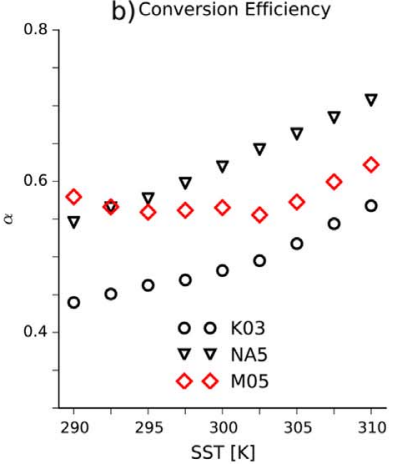

c) Sedimentation Efficiency

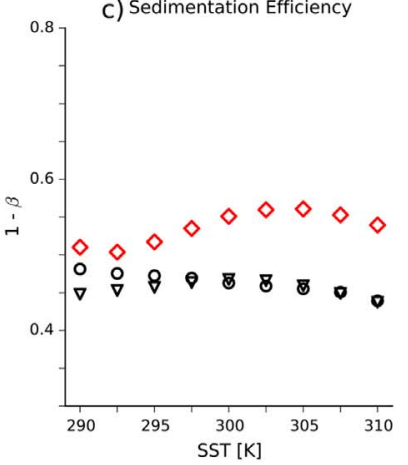

Figure 4. (a) Precipitation efficiency versus SST for three sets of CRM simulations. K03 and NA5 use single-moment microphysics, while M05 uses double-moment microphysics. (b) Contribution from conversion efficiency $\alpha$. (c) Contribution from sedimentation efficiency $1-\beta$. Figure after (Lutsko and Cronin 2018), reproduced with permission.

In the aforementioned CRM studies, the changes in $\epsilon$ with warming of a few degrees were empirically found to be small, at least without convective organization. A recent study addressed this question in CRM simulations over a wider range of SSTs (Lutsko and Cronin 2018). They investigate the domain-mean $\epsilon$, which is likely different from precipitation efficiency at extremes, since the domain mean includes shallow convection with low efficiency compared to deep convection. Still the results help shed some light into the response to warming and the sensitivity to details of the microphysics.

The precipitation efficiency $\epsilon$ can be split into two contributions (Langhans et al 2015)

$$
\epsilon=\alpha(1-\beta) .
$$

In a first step, a fraction $\alpha$ of cloud condensates is converted into precipitation. $\alpha$ is thus a conversion efficiency. The remaining fraction $(1-\alpha)$ of cloud condensates either stays suspended as a cloud or is detrained from the convective region and evaporates. In a second step, a fraction $\beta$ of the precipitation evaporates as it falls through subsaturated air. $(1-\beta)$ is thus a sedimentation efficiency (probability that a precipitating hydrometeor reaches the surface), and the total amount reaching the surface is given by (15).

Both contributions are expected to be sensitive to details of the microphysics. Notably, in the singlemoment microphysic schemes used in Lutsko and Cronin (2018), the autoconversion is carried out by a fractional removal scheme when the mixing ratio of cloud condensates $q_{c}$ exceeds a threshold $q_{c, 0}$

$$
\frac{\partial q_{p}}{\partial t}=\max \left(0, \eta\left[q_{c}-q_{c, 0}\right]\right),
$$

where $q_{p}$ is the mixing ratio of precipitating species, and $\eta$ an autoconversion rate coefficient (this equation applies to both liquid and ice phases but with different coefficients). A different, double-moment microphysic scheme is also investigated. In both cases, to leading-order, the evaporation of precipitation can be assumed to scale with the saturation deficit $\propto(1-\mathrm{RH})$, and with the fall time $\tau$ :

$$
\beta \sim(1-R H) \times \tau .
$$

Despite different values of $\epsilon$ with the different microphysics (single-moment versus doublemoment), its response to warming is surprisingly robust, with an increase of about $1 \% \mathrm{~K}^{-1}$ for SSTs between 292.5 and $310 \mathrm{~K}$ (figure 4). But the attribution depends on the microphysic scheme. With singlemoment microphysics, the increase is entirely due to increased conversion efficiency. This increased conversion efficiency follows from larger cloud condensate amounts, resulting in the autoconversion threshold in (16) being exceeded more often. In the two-moment microphysic scheme, it is due to increased sedimentation efficiency at SSTs below $302.5 \mathrm{~K}$, and to increased conversion efficiency above.

The two-moment scheme below $302.5 \mathrm{~K}$ differs from the single-moment scheme, because the larger cloud condensate amount in that case is offset by higher precipitation source heights, where cloud condensate amounts are not as sensitive to SST. Once $302.5 \mathrm{~K}$ is reached though, the precipitation source heights reach lower altitudes, and the larger cloud condensate amounts there affect the conversion efficiency as in the single-moment microphysics. The contribution from sedimentation efficiency also differs between the single-moment and the double-moment microphysics, due to different sensitivities of saturation deficit and hydrometeor fall speeds to warming (see Lutsko and Cronin 2018 for more details).

Overall, these results and the significant sensitivity to the microphysic scheme highlight the importance of accurately representing microphysical processes, and in particular the height and thus temperature at which precipitation forms As mentioned earlier, these results pertain to large-scale precipitation efficiency. There will likely be some differences between precipitation efficiency at large scales and convective scales. The latter has been the focus of a recent observational study (Narsey et al 2019), yielding the first estimate of precipitation efficiency (defined as in equation (4)) at convective scales in the tropics. Larger precipitation rates are associated with higher 
efficiency, while larger CAPE is associated with lower efficiency. Also, as expected from basic theory, precipitation efficiency increases with midtropospheric moisture. It is unclear from idealized modeling studies whether precipitation efficiency should remain the same (Muller et al 2011) or potentially increase (Singh and O'Gorman 2014, Lutsko and Cronin 2018) with surface warming. The presence of convective organization can also strongly impact the precipitation efficiency, with intriguing sensitivity to the microphysics (and notably the fall speed of hydrometeors) (Bao and Sherwood 2019), which deserves further investigation.

\section{Precipitation extremes in observations, and importance of organized convection}

The relationship between precipitation extremes and temperature in our current climate has been widely investigated in observations (e.g. Trenberth and Shea 2005, Lenderink and van Meijgaard 2008, Hardwick Jones et al 2010, Utsumi et al 2011). Difficulties may arise when this relationship is extrapolated to the relationship between precipitation extremes and temperature changes due to global warming, since the response of precipitation extremes to temperature changes due to climate natural variability is not necessarily the same as the response due to climate change (e.g. O'Gorman 2012, Drobinski et al 2016b, Bao et al 2017). Still, in any event, investigations of processes which bring precipitation extremes in our current climate should shed some light on projections of precipitation extremes in future climate.

As mentioned in the introduction, there is now strong observational evidence of significant departures from the theoretical CC-scaling. One contribution to these departures is aridity at the warmest temperatures over land, which can lead to a decrease of precipitation extremes with temperature at the warmest temperatures (Westra et al 2014). Indeed, although rainfall intensity scales positively with integrated water vapor, integrated water vapor does not consistently scale positively with surface air temperature, as extreme temperature days can be associated with insufficient surface moisture (Roderick et al 2019). In this special ERL issue, (Roca 2019) confirms the decreasing regime after a peak temperature for daily precipitation extremes over tropical land. At intermediate temperatures though, a CC-like scaling is observed, while a flat regime is identified at colder temperatures, whose origin is unclear (Roca 2019). Since moisture availability becomes the dominant driver of extreme precipitation at higher temperatures, a number of studies have suggested the use of dew point temperature as a scaling variable, to overcome humidity limitations. Consistently, the scaling for daily precipitation extremes becomes more consistent in space by using dew point temperature as a scaling variable instead of surface air temperature (Ali et al 2018).
Also, as noted in the introduction, the sensitivity of subdaily precipitation extremes to warming may be different from the sensitivity of daily precipitation extremes. More generally, impacts of temporal/spatial averaging have been reported (e.g. Utsumi et al 2011), which could be attributable to event duration and/or different precipitation types. Indeed, different precipitation types have different duration, and from observations we have been aware of variations of precipitation types affecting the sensitivity of precipitation to temperature change.

First, an apparent distinction can be found between large-scale precipitation, observed more in mid-latitudes, and convective precipitation, observed more in the tropics. Berg et al (2013) separated stratiform (large-scale) and convective precipitation by combining the radar and rain gauge observations in Germany, and showed a clear difference in precipitation dependence on temperature between the two types of rainfall. Namely, large-scale stratiform precipitation followed the Clausius-Clapeyron (CC) relationship, while the convective precipitation was more sensitive to temperature. Further, (Berg and Haerter 2013) indicated that a super-CC scaling occurs at the transition temperature between the above two types of rainfall. Seasonal effects in precipitation extremes in the south of France were also suggested by Drobinski et al (2016a), and attributed to seasonal precipitation type differences, from large-scale to convection.

Secondly, in a warmer range of temperature, we are further aware of at least two distinct types of convective precipitation extremes. Conventionally, we have assumed that the most active kind of convection causes the heaviest precipitation, which we experience in our daily lives. However, accumulation of threedimensional data of precipitation systems observed from space-borne precipitation radars, namely, Tropical Rainfall Measuring Mission/Precipitation Radar (TRMM/PR) and Global Precipitation Measurement/ Dual-frequency Precipitation Radar (GPM/DPR), made us reconsider this conventional assumption.

Hamada et al (2015) investigated more than 135 million tropical and subtropical precipitation events, which are the contiguous features of radar-observed precipitation systems obtained from 12 years of TRMM PR2A25 data. By accumulating precipitation events in each $2.5^{\circ} \times 2.5^{\circ}$ latitude-longitude grids, they picked up the top 0.1 percentile extremes for convection and rainfall intensities, separately, in each grid. Convection extremes were defined with the maximum height of $40 \mathrm{dBZ}$ reflectivity in each rainfall event, and precipitation extremes were defined with the maximum pixel intensity at near surface, respectively. As a result, it was shown that only $10 \%$ of each extremes satisfy the other extremes criteria. Moreover, from a comparison of vertical profiles of precipitation intensity histograms, it was shown that convection extremes are associated with a lot of cold-type rain 
GLB, Land, ANN, v7f, p999

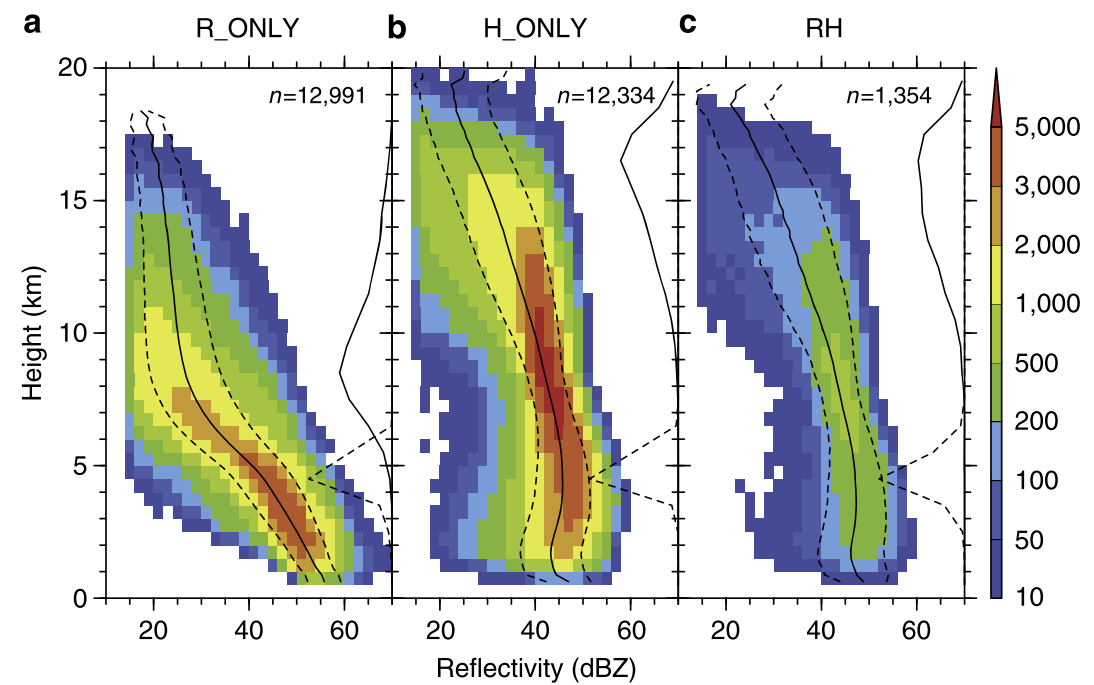

Figure 5. Composite structures of radar reflectivity at extreme pixels within the TRMM observation domain $\left(37.5^{\circ} \mathrm{S}-37.5^{\circ} \mathrm{N}\right)$. Colours show joint histograms of effective radar reflectivity and height, superimposed by solid and dashed lines that indicate the mean and s.d. for each height bin, respectively. Solid and dashed lines along the right-hand axis of each panel show the histograms of echo-top heights and $0{ }^{\circ} \mathrm{C}$ levels, respectively. The number of samples for the corresponding extreme type is indicated. (a)-(c) R-only (extreme rainfall event), H-only (extreme convective event) and $\mathrm{RH}$ (both an extreme rainfall and extreme convective event) over land, respectively; adapted from Hamada et al (2015), reproduced with permission.

which consists of a lot of solid precipitation in the upper levels, while precipitation extremes have comparatively shallower structure, indicating a dominance of warm-type rainfalls (figure 5). The environmental conditions for each extremes also differ, in the manner that the convective systems are embedded in environments with large instability, while precipitation extremes are embedded in environments with deep moist layer in the troposphere, but the atmospheric stratification is relatively more stable.

Hamada and Takayabu (2018) further explored the extreme convection and extreme rainfall in a region around Japan in midsummer. In their study, it was found that the extreme convection had smaller area size and was accompanied by much more frequent lightening, while extreme rainfall had relatively larger area size with larger stratiform ratio and much less lightening. These results indicate that extreme convection is rather an isolated plume under an unstable environment, while extreme rainfall often comes from organized systems in a very moist environment.

The above results are also in concert with a finding by Sohn et al (2013) that heavy rainfall in moist monsoon regions, like over Korea, consist largely of warmtype rainfall, while heavy precipitation comes from cold-type rainfall in drier regions as in Oklahoma, US. Bretherton et al (2004) pointed out that tropical precipitation picks up drastically with a certain column water vapor (CWV), or more generally, with a certain column relative humidity $(\mathrm{CRH})$ over the tropical oceans. Ahmed and Schumacher (2015) further utilized the TRMM PR data to partition the contributions to the precipitation pickup with the $\mathrm{CRH}$, into different types of rainfalls. As a result, they suggested that stratiform precipitation from organized systems contribute to the CWV dependence.

More recently, (Yokoyama et al 2019) utilized the three-dimensional radar observations from the GPM DPR, to separate the precipitation system around Japan in warm seasons into three types, namely, midlatitude type, small type, and organized type. They showed that dependencies of occurrence frequencies on environmental conditions differ in those three types. Among the latter two convective types, small type precipitation obeys more to sea-surface temperature, while organized types are more controlled by the state of large-scale circulation. Combined with future large-scale environmental variables obtained from CMIP5 RCP8.5 data, they alert a projection that the organized type, which often causes disastrous rainfall in the western part of Japan, will increase in the northern part of Japan in the future.

The above studies indicate the importance of organized systems in extreme precipitation in the warmer range. Organized systems occur more frequently in a moister but not necessarily unstable condition. On the other hand, extreme convection in unstable (largeCAPE) condition occur more with rather isolated small-scale precipitation systems. Here we emphasize that we are now observationally aware of distinct dependencies on environments between isolated convection and organized systems. The observational studies also highlight the need to improve our fundamental understanding of mesoscale convective organization and its response to warming, to achieve accurate projections of precipitation extremes in our changing climate. 


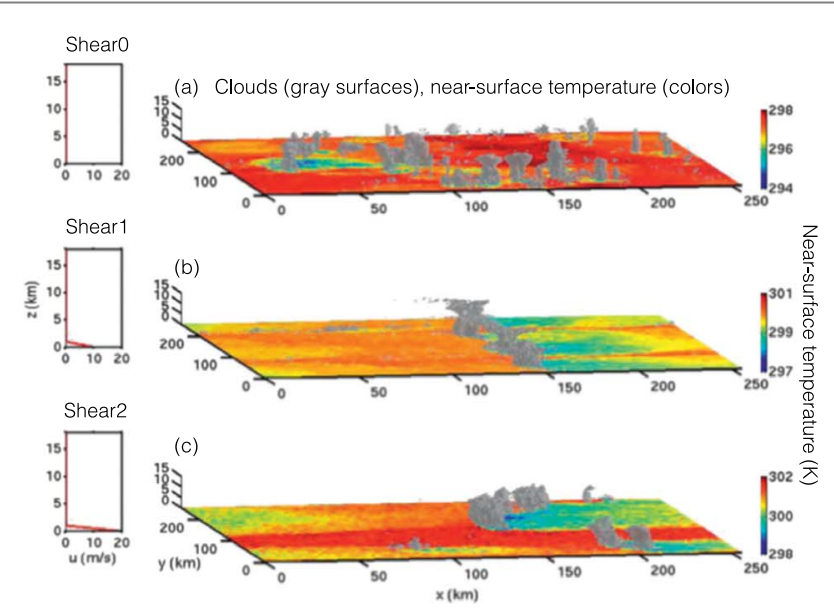

(d)

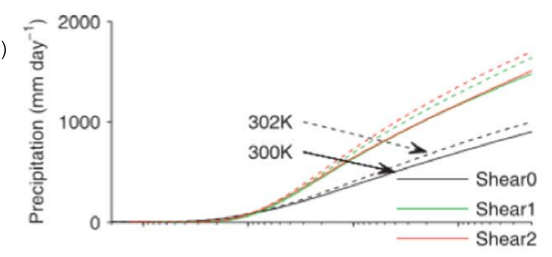

(e)

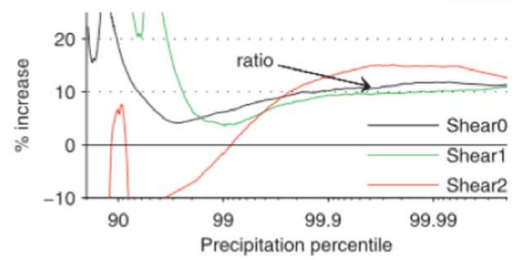

Figure 6. (a)-(c) Snapshots of CRM simulations with various mean vertical shears, imposed to organize the convection into squall lines. (a) Shear0: no shear; (b) Shear 1: $10 \mathrm{~m} \mathrm{~s}^{-1}$ surface wind decreasing to 0 at $1 \mathrm{~km}$; (c) Shear2: twice Shear1. With both Shear1 and Shear2, the convection organizes into squall lines. (d) Response of precipitation extremes (high percentiles) to the organization, and (e) to a 2 K SST warming (from 300 to $302 \mathrm{~K}$ ). The organization (going from Shear0 to either Shear1 or Shear2) results in almost a doubling of extremes, which a $2 \mathrm{~K}$ warming results in an amplification of about $7 \% \mathrm{~K}^{-1}$; figure adapted from Muller (2013), reproduced with permission, copyright [2013] AMS.

\section{Conclusions and outstanding questions}

Improved fundamental understanding of deep convection, partly thanks to idealized CRM studies, have allowed to robustly predict an amplification of precipitation extremes with warming. This can be understood from simple thermodynamics, with an increase at a rate of about $6 \%-7 \% \mathrm{~K}^{-1}$ following the lowtropospheric humidity as dictated by the ClausiusClapeyron equation (Held and Soden 2006, O'Gorman and Schneider 2009, Muller et al 2011). This rate of increase of low-tropospheric humidity is slower than the increase in atmospheric humidity (O'Gorman and Muller 2010).

Beyond this thermodynamic theoretical expectation, the dynamics, via increased vertical mass flux in extreme updrafts, and the microphysics, via increased precipitation efficiency, can further amplify the response of precipitation extremes to warming. In fact, there is now ample observational evidence of departures from the theoretical CC scaling. Even within the limits of the idealized studies reviewed here, precipitation extremes only follow the thermodynamic theoretical expectation for the highest percentiles (above the 99.9th percentile or so; see also Pendergrass 2018 for a discussion of the sensitivity to the definition of extremes). Without a complete theory for the dynamical and microphysical changes with warming, we can not properly attribute causes for the corresponding contributions to extreme rainfall rates. More work is desirable in particular to clarify the relative roles of convective entrainment (e.g. Seeley and Romps 2015, Singh and O'Gorman 2015), hydrometeor fall speeds (e.g. Parodi and Emanuel 2009, Bao and Sherwood 2019), and atmospheric stability (e.g. Attema et al 2014, Hamada and Takayabu 2018), as well as microphysical processes including cloud-rain autoconversion and rain evaporation (e.g. Lutsko and Cronin 2018).

Notably, increased atmospheric instability can lead to an amplification of precipitation extremes exceeding significantly the thermodynamic theoretical expectation, with faster updrafts contributing positively to the dynamic contribution. We note however that the link between stability and precipitation extremes is not necessarily straightforward. Differences in atmospheric stability may result in differences in convection, but extremes in precipitation intensity do not necessarily follow the atmospheric stability (Hamada et al 2015). This suggests that changes in atmospheric stability associated with sub-daily extreme precipitation events, and the corresponding dynamic contribution to precipitation extremes, need to be clarified.

Note also that a large uncertainty regarding tropical precipitation extremes and their response to warming, is related to convective organization and its response to warming. Most CRM studies discussed earlier did not include mesoscale convective organization. In the tropics, a large amount of rainfall is associated with organized systems (Houze 2004, Hamada et al 2015). Muller (2013) investigated the impact of mesoscale convective organization on the response of precipitation extremes to warming. For a given level of convective organization (squall lines in that study, obtained by imposing a vertical wind shear figures $6(\mathrm{a})-(\mathrm{c}))$, the amplification of precipitation extremes is again found to be given to leading order by the thermodynamic contribution, close to low-tropospheric water vapor about $7 \% \mathrm{~K}^{-1}$. But the amplification of precipitation extremes due to organization for a given SST, is found to be significantly larger than the amplification due to warming by five degrees for a given level of organization (figures 6(d) and (e)). Thus, a large uncertainty in our current estimates of 
changing precipitation with warming comes from lack of knowledge of how convective organization will change with warming.

This important question is beyond the scope of this paper, and will be discussed in more detail in a separate paper specifically devoted to convective organization. But briefly, when the atmosphere is more organized into a moist convecting region, and a dry convection-free region, the moister environment of deep convective updrafts is expected to enhance the thermodynamic contribution as well as the microphysic contribution through larger precipitation efficiency (reduced evaporation of rain falling through a moister near-cloud environment). The dynamics and duration of precipitating events are also affected, thus the amplification of precipitation extremes could be much larger than the thermodynamic theoretical expectation (Bao and Sherwood 2019).

Recent observations show that most of the regional increase of tropical precipitation is associated with changes in the frequency of organized convection (Tan et al 2015). Improved fundamental understanding of convective organization and its sensitivity to warming is hence an area of priority for climate model development to achieve accurate rainfall projections in a warming climate.

\section{Acknowledgments}

CJM gratefully acknowledges funding from the European Research Council (ERC) under the European Union's Horizon 2020 research and innovation programme (Project CLUSTER, grant agreement No. 805041), from the French national program Les Enveloppes Fluides et l'Environnement (LEFE) of Institut National des Sciences de l'Univers (INSU), and from the program Paris Sciences et Lettres PSLNYU (ANR-10-IDEX-0001-02). The authors also thank Grand Équipement National De Calcul Intensif (GENCI), France, for providing access and support to their computing platforms Très Grand Centre de Calcul (TGCC). The authors would also like to thank the anonymous reviewers for their useful comments.

\section{Data availability statement}

The data that support the findings of this study are available from the corresponding author upon reasonable request.

\section{References}

Abbott T H, Cronin T W and Beucler T 2019 Convective dynamics and the response of precipitation extremes to warming in radiative-convective equilibrium arXiv:1909.01941v2[physics.ao-ph]

Agard V and Emanuel K 2017 Clausius-Clapeyron scaling of peak cape in continental convective storm environments J. Atmos. Sci. $743043-54$
Ahmed F and Schumacher C 2015 Convective and stratiform components of the precipitation? Moisture relationship Geophys. Res. Lett. 42 10453-62

Ali H, Fowler H J and Mishra V 2018 Global observational evidence of strong linkage between dew point temperature and precipitation extremes Geophys. Res. Lett. 45 12-320

Allen M R and Ingram W J 2002 Constraints on future changes in climate and the hydrologic cycle Nature 419 224-32

Attema J J, Loriaux J M and Lenderink G 2014 Extreme precipitation response to climate perturbations in an atmospheric mesoscale model Environ. Res. Lett. 9014003

Bao J and Sherwood S C 2019 The role of convective self-aggregation in extreme instantaneous versus daily precipitation J. Adv. Model. Earth Syst. 11 19-33

Bao J, Sherwood S C, Alexander L V and Evans J P 2017 Future increases in extreme precipitation exceed observed scaling rates Nat. Clim. Change 7128

Berg P and Haerter J O 2013 Unexpected increase in precipitation intensity with temperature-a result of mixing of precipitation types? Atmos. Res. 11956-61

Berg P, Moseley C and Haerter J O 2013 Strong increase in convective precipitation in response to higher temperature Nat. Geosci. 6 181-5

Betts A K 1998 Climate-convection feedbacks: some further issues Clim. Change 39 35-8

Betts A K and Harshvardhan 1987 Thermodynamic constraint on the cloud liquid water feedback in climate models J. Geophys. Res. 92 8483-5

Bretherton C S, Peters M E and Back L E 2004 Relationships between water vapor path and precipitation over the tropical oceans J. Clim. 17 1517-28

Brooks H E, Doswell C A III and Cooper J 1994 On the environments of tornadic and nontornadic mesocyclones Wea. Forecast. $9606-18$

Drobinski P, Alonzo B, Bastin S, Da Silva N and Muller C 2016a Scaling of precipitation extremes with temperature in the french mediterranean region: what explains the hook shape? J. Geophys. Res. $1213100-19$

Drobinski P et al 2016b Scaling precipitation extremes with temperature in the mediterranean: past climate assessment and projection in anthropogenic scenarios Clim. Dyn. 51 1237-57

Hamada A and Takayabu Y N 2018 Large-scale environmental conditions related to midsummer extreme rainfall events around Japan in the TRMM region J. Clim. 31 6933-45

Hamada A, Takayabu Y N, Liu C and Zipser E J 2015 Weak linkage between the heaviest rainfall and tallest storms Nat. Commun. 66213

Hardwick Jones R, Westra S and Sharma A 2010 Observed relationships between extreme sub-daily precipitation, surface temperature, and relative humidity Geophys. Res. Lett. 37 L22805

Hartmann D L and Larson K 2002 An important constraint on tropical cloud-climate feedback Geophys. Res. Lett. 291951

Held I M and Soden B J 2006 Robust responses of the hydrological cycle to global warming J. Clim. 195686-99

Holloway C E and Neelin J D 2009 Moisture vertical structure, column water vapor, and tropical deep convection J. Atmos. Sci. 66 1665-83

Houze R A Jr 2004 Mesoscale convective systems Rev. Geophys. 42 RG4003

Iribarne J V and Godson W L 1981 Atmospheric Thermodynamics (Berlin: Springer) section 9.14

Khairoutdinov M F and Randall D A 2003 Cloud-resolving modeling of the arm summer 1997 IOP: model formulation results, uncertainties and sensitivities J. Atmos. Sci. 60 607-25

Kharin V V, Zwiers F W, Zhang X and Hegerl G C 2007 Changes in temperature and precipitation extremes in the ipcc ensemble of global coupled model simulations J. Clim. 20 1419-44

Langhans W, Yeo K and Romps D M 2015 Lagrangian investigation of the precipitation efficiency of convective clouds J. Atmos. Sci. 72 1045-62 
Lenderink G, Belušić D, Fowler H J, Kjellström E, Lind P, van Meijgaard E, van Ulft B and de Vries H 2019 Systematic increases in the thermodynamic response of hourly precipitation extremes in an idealized warming experiment with a convection-permitting climate model Environ. Res. Lett. 14 L074012

Lenderink G and van Meijgaard E 2008 Increase in hourly precipitation extremes beyond expectations from temperature changes Nat. Geosci. 1511-4

Lepore C, Veneziano D and Molini A 2015 Temperature and cape dependence of rainfall extremes in the eastern United States Geophys. Res. Lett. 42 74-83

Loriaux J M, Lenderink G, De Roode S R and Siebesma A P 2013 Understanding convective extreme precipitation scaling using observations and an entraining plume model J. Atmos. Sci. 70 3641-55

Lutsko N J and Cronin T W 2018 Increase in precipitation efficiency with surface warming in radiative-convective equilibrium J. Adv. Model. Earth Syst. 10 2992-3010

Muller C J 2013 Impact of convective organization on the response of tropical precipitation extremes to warming J. Clim. 265028-43

Muller C J and O'Gorman P A 2011 An energetic perspective on the regional response of precipitation to climate change $\mathrm{Nat}$. Clim. Change $1266-71$

Muller C J, O'Gorman P A and Back L E 2011 Intensification of precipitation extremes with warming in a cloud-resolving model J. Clim. 24 2784-800

Narsey S, Jakob C, Singh M S, Bergemann M, LoufV, Protat A and Williams C 2019 Convective precipitation efficiency observed in the tropics Geophys. Res. Lett. 46 13574-83

O'Gorman P A 2012 Sensitivity of tropical precipitation extremes to climate change Nat. Geosci. 5697

O'Gorman P A 2015 Precipitation extremes under climate change Curr. Clim. Change Rep. 149-59

O'Gorman P A and Muller C J 2010 How closely do changes in surface and column water vapor follow Clausius-Clapeyron scaling in climate-change simulations? Environ. Res. Lett. 5 025207

O'Gorman P A and Schneider T 2009 The physical basis for increases in precipitation extremes in simulations of XXIcentury climate change Proc. Natl Acad. Sci. 106 14773-7

Pall P, Allen M R and Stone D A 2007 Testing the ClausiusClapeyron constraint on changes in extreme precipitation under $\mathrm{CO}_{2}$ warming Clim. Dyn. 28351-63

Parodi A and Emanuel K A 2009 A theory for buoyancy and velocity scales in deep moist convection J. Atmos. Sci. 66 3449-63

Pendergrass A G 2018 What precipitation is extreme? Science 360 $1072-3$

Pendergrass A G and Gerber E P 2016 The rain is askew: two idealized models relating vertical velocity and precipitation distributions in a warming world J. Clim. 29 6445-62

Pfahl S, O'Gorman P A and Fischer E M 2017 Understanding the regional pattern of projected future changes in extreme precipitation Nat. Clim. Change 7423

Popke D, Stevens B and Voigt A 2013 Climate and climate change in a radiative-convective equilibrium version of ECHAM6 J. Adv. Model. Earth Syst. 51-14

Roca R 2019 Estimation of extreme daily precipitation thermodynamic scaling using gridded satellite precipitation products over tropical land Environ. Res. Lett. 14095009
Roderick T P, Wasko C and Sharma A 2019 Atmospheric moisture measurements explain increases in tropical rainfall extremes Geophys. Res. Lett. 46 1375-82

Romps D M 2011 Response of tropical precipitation to global warming J. Atmos. Sci. 68 123-38

Romps D M and Kuang Z 2010 Do undiluted convective plumes exist in the upper tropical troposphere? J. Atmos. Sci. 67 468-84

Schär C et al 2016 Percentile indices for assessing changes in heavy precipitation events Clim. Change 137 201-16

Seeley J T and Romps D M 2015 Why does tropical convective available potential energy (cape) increase with warming? Geophys. Res. Lett. 42 10-429

Singh M S and O'Gorman P A 2013 Influence of entrainment on the thermal stratification in simulations of radiative-convective equilibrium Geophys. Res. Lett. 40 4398-403

Singh M S and O'Gorman P A 2014 Influence of microphysics on the scaling of precipitation extremes with temperature Geophys. Res. Lett. 41 6037-44

Singh M S and O'Gorman P A 2015 Increases in moist-convective updraught velocities with warming in radiative-convective equilibrium Q. J. R. Meteor. Soc. 141 2828-38

Singleton A and Toumi R 2013 Super clausius-clapeyron scaling of rainfall in a model squall line Q. J. R. Meteor. Soc. 139334-9

Sohn B J, Ryu G-H, Song H-J and Ou M-L 2013 Characteristic features of warm-type rain producing heavy rainfall over the korean peninsula inferred from trmm measurements Mon. Wea. Rev. $1413873-88$

Su H, Zhai C, Jiang J H, Wu L, Neelin J D and Yung Y L 2019 A dichotomy between model responses of tropical ascent and descent to surface warming NPJ Clim. Atmos. Sci. 28

Sugiyama M, Shiogama H and Emori S 2010 Precipitation extreme changes exceeding moisture content increases in MIROC and IPCC climate models Proc. Natl Acad. Sci. 107 571-5

Tan J, Jakob C, Rossow W B and Tselioudis G 2015 Increases in tropical rainfall driven by changes in frequency of organized deep convection Nature 519451

Tiedtke M 1989 A comprehensive mass flux scheme for cumulus parameterization in large-scale models Mon. Wea. Rev. 117 1779-800

Trenberth KE 1998 Atmospheric moisture residence times and cycling: implications for rainfall rates and climate change Clim. Change 39 667-94

Trenberth K E, Dai A, Rasmussen R M and Parsons D B 2003 The changing character of precipitation Bull. Am. Meteor. Soc. 84 1205-18

Trenberth K E and Shea D J 2005 Relationships between precipitation and surface temperature Geophys. Res. Lett. 32 L14703

Utsumi N, Seto S, Kanae S, Maeda E and Oki T 2011 Does higher surface temperature intensify extreme precipitation? Geophys. Res. Lett. 38 L16708

Westra S, Fowler H, Evans J, Alexander L, Berg P, Johnson F, Kendon E, Lenderink G and Roberts N 2014 Future changes to the intensity and frequency of short-duration extreme rainfall Rev. Geophys. 52 522-55

Yokoyama C, Takayabu Y N, Arakawa O and Ose T 2019 A study on future projections of precipitation characteristics around Japan in early summer combining GPM DPR observation and CMIP5 large-scale environments J. Clim. 32 5251-74 